\title{
The Contribution of Facilitation of Monosynaptic PSPs to Dishabituation and Sensitization of the Aplysia Siphon Withdrawal Reflex
}

\author{
Igor Antonov, ${ }^{1}$ Eric R. Kandel, ${ }^{1,2,3}$ and Robert D. Hawkins ${ }^{1,2}$ \\ ${ }^{1}$ Center for Neurobiology and Behavior, College of Physicians and Surgeons, Columbia University, New York, New York \\ 10032, and 2New York State Psychiatric Institute and ${ }^{3 H}$ Howard Hughes Medical Institute, New York, New York 10032
}

\begin{abstract}
To examine the relationship between synaptic plasticity and learning and memory as directly as possible, we have developed a new simplified preparation for studying the siphonwithdrawal reflex of Aplysia in which it is relatively easy to record synaptic connections between individual identified neurons during simple forms of learning. We estimated that monosynaptic EPSPs from LE siphon sensory neurons to LFS siphon motor neurons mediate approximately one-third of the reflex response measured in this preparation, which corresponds to siphon flaring in the intact animal. To investigate cellular mechanisms contributing to dishabituation and sensitization, we recorded evoked firing of LFS neurons, the siphon withdrawal produced by stimulation of an LFS neuron, the complex PSP in an LFS neuron, and the monosynaptic PSP from an "on-field" or "off-field" LE neuron to an LFS neuron during behavioral training. Unlike the simplified gill-withdrawal preparation (Co-
\end{abstract}

Many theories of learning have proposed that plasticity at specific synapses in the CNS is critical for memory storage, and a number of mechanisms of synaptic plasticity have been identified that might contribute to learning and memory (Hawkins et al., 1987; Ito, 1989; Antonov et al., 1991; Bliss and Collingridge, 1993; Linden and Connor, 1995). However, in most cases it has been very difficult to test the causal relationship between these mechanisms and learning. The gill- and siphon-withdrawal reflex of Aplysia is advantageous for such an analysis, and previous studies have suggested that several simple forms of learning of the reflex are caused in part by plasticity at synapses of the siphon sensory neurons (for review, see Hawkins et al., 1993). However, even in this simple system it has proven surprisingly difficult to demonstrate a direct relationship between the synaptic plasticity and learning. Most previous studies of the reflex have involved behavioral experiments in the intact animal and either cellular analogs or correlates in the isolated nervous system, which are only indirectly related to the behavior. A few studies have attempted to bridge the cellular and behavioral levels more directly by examining the sensory neuron synapses and behavior in the same

Received June 7, 1999; revised July 30, 1999; accepted Sept. 13, 1999.

This work was supported by a grant from the National Institute of Mental Health (MH26212). We thank J. Koester, I. Kupfermann, and C. Rankin for their comments, H. Ayers and M. Pellan for typing this manuscript, and C. Lam for preparing the figures.

Correspondence should be addressed to Dr. Robert D. Hawkins, Center for Neurobiology and Behavior, Columbia University College of Physicians and Surgeons, 722 West 168th Street, New York, NY 10032. E-mail: rhawkins @pi.cpmc. columbia.edu.

Copyright (C) 1999 Society for Neuroscience $0270-6474 / 99 / 1910438-13 \$ 05.00 / 0$ hen et al., 1997; Frost et al., 1997), in the siphon-withdrawal preparation we found no qualitative differences between the major cellular mechanisms contributing to dishabituation and sensitization, suggesting that dissociations that have been observed previously may be attributable to transient inhibition that does not occur for this component of the reflex. Furthermore, in the siphon-withdrawal preparation, all of the various cellular measures, including monosynaptic PSPs from either on-field or off-field LE neurons, changed approximately in parallel with changes in the behavior. These results provide the most direct evidence so far available that both dishabituation and sensitization involve multiple mechanisms, including heterosynaptic facilitation of sensory neuron-motor neuron PSPs.

Key words: facilitation; PSP; dishabituation; sensitization; Aplysia; learning

preparation (Byrne et al., 1978; Lukowiak, 1986; Wright et al., 1991). However, from these and other studies (Jacklet and Rine, 1977; Kanz et al., 1979; Hawkins et al., 1981; Colebrook and Lukowiak, 1988; Frost et al., 1988; Trudeau and Castellucci, 1993), it has become clear that plasticity of the behavior is determined by multiple mechanisms of cellular plasticity at a number of loci, so that any one mechanism may not correlate well with the behavior. Furthermore, the contribution of each mechanism appears to depend on the particular experimental procedures such as the stimuli used and the response measured, making comparisons between studies with different procedures problematic (Hawkins et al., 1998a).

For these reasons, it seemed desirable to be able to study cellular mechanisms and learning simultaneously in as simple a behavioral system as possible. Toward that end, we have developed a new preparation with which it is relatively easy to measure reflex contraction of the siphon while simultaneously recording from one or more neurons in the ganglion with intracellular electrodes and thus to relate the cellular events to behavior. This preparation exhibits several simple forms of learning with properties generally similar to learning in the intact animal (Carew et al., 1981; Hawkins et al., 1998a). The reflex response is mediated in part by monosynaptic connections from the LE sensory neurons to LFS motor neurons, which exhibit several types of plasticity, including analogs of these forms of learning (Hawkins et al., 1983; Mackey et al., 1987; Wright et al., 1991). We have now been able to use this preparation to provide the first direct evidence that heterosynaptic facilitation of the monosynaptic PSPs contributes to learning and memory for dishabituation and sensitization 
of the withdrawal reflex and to show that other sites and mechanisms of plasticity also contribute.

\section{MATERIALS AND METHODS}

Aplysia californica weighing 100-150 gm were obtained from Marinus (Long Beach, CA). They were housed in individual containers in a large aquarium with circulating artificial seawater (Instant Ocean, Aquarium Systems, Mentor, $\mathrm{OH}$ ) at $15^{\circ} \mathrm{C}$ on a $12 \mathrm{hr}$ light/dark cycle and fooddeprived for several days before an experiment was begun to try to minimize variability in their motivational state. The animals were anesthetized by injection of $50 \mathrm{ml}$ of isotonic $\mathrm{MgCl}_{2}$, and the siphon, tail, and CNS were dissected out in $50 \% \mathrm{MgCl}_{2}, 50 \%$ artificial seawater. The siphon was cut partially in half along the longitudinal axis, and the abdominal ganglion was dipped in $0.5 \%$ glutaraldehyde for $60 \mathrm{sec}$ to kill muscle cells in the sheath. The preparation was then pinned to the Sylgard floor of a Lucite recording chamber filled with circulating, aerated artificial seawater at room temperature (see Fig. $1 A$ ). One-half of the cut part of the siphon was not pinned. Seawater was injected into the tail and siphon to flush out the $\mathrm{MgCl}_{2}$, and the abdominal ganglion was partially desheathed.

An LE siphon mechanosensory neuron, identified by its electrophysiological properties and response to siphon stimulation (Byrne et al., 1974), was impaled with a single-barreled glass microelectrode filled with $2.5 \mathrm{M} \mathrm{KCl}$, and an $\mathrm{LFS}_{\mathrm{B}}$ siphon motor neuron, identified by its electrophysiological properties and siphon movement (Frost et al., 1988), was impaled with a double-barreled microelectrode. In some experiments, current was passed through one barrel of the electrode either to hyperpolarize the motor neuron $\sim 30 \mathrm{mV}$ below resting potential and prevent spiking during the siphon stimulation or to depolarize the neuron and cause spiking. Mechanical stimulation (taps) was delivered to the pinned half of the siphon with a controlled force stimulator identical to the one used by Cohen et al. (1997). The tip of the stimulator was a $1.5-\mathrm{mm}$ diameter stainless steel rod, tap duration was $500 \mathrm{msec}$, and tap pressure was usually $\sim 20 \mathrm{gm} / \mathrm{mm}^{2}$ [calibrated against a strain gauge transducer (Grass Instruments, Quincy, MA)], which is considered to be relatively innocuous (Walters and Cohen, 1997). Withdrawal of the other half of the siphon, which was not pinned, was recorded with a low mass isotonic transducer (Harvard Apparatus, South Natick, MA) connected to the siphon with a silk suture. The component of contraction that was measured with this recording system would probably contribute to backward bending or "flaring" of the siphon in the intact animal. During dishabituation and sensitization training, the tail was stimulated with a train of four $60 \mathrm{~Hz}$ AC electrical shocks [1.0 sec duration, $2 \mathrm{sec}$ interstimulus interval (ISI), $25 \mathrm{~mA}$ ] delivered via fixed capillary electrodes. Preparations were considered unhealthy and excluded from the results if the shock produced a siphon withdrawal of $<3 \mathrm{~mm}$, which occurred in $\sim 25 \%$ of dishabituation and sensitization experiments.

The preparation was rested for at least $1 \mathrm{hr}$ before the beginning of dishabituation or sensitization training (see Fig. $1 B$ ). During habituation and dishabituation, the siphon was stimulated eight times with a $5 \mathrm{~min}$ intertrial interval, and habituation was measured as the decrease in responding on trial 5 compared with trial 1 . The tail was then shocked 2.5 min after trial 5 , and dishabituation was measured as the increase in responding on trials 6,7 , and 8 compared with trial 5. During sensitization, there was a single siphon stimulation (trial 1) followed by $1 \mathrm{hr}$ rest to minimize habituation. The tail was then shocked, and the siphon was stimulated again for $2.5 \mathrm{~min}$ (trial 2), $7.5 \mathrm{~min}$ (trial 3), and $12.5 \mathrm{~min}$ (trial 4) after the shock. Sensitization was measured as the increase in responding on trials 2,3 , and 4 , compared with trial 1 . During both dishabituation and sensitization, experiments were continued only if the siphon withdrawal on trial 1 was between 0.5 and $3 \mathrm{~mm}$ (the maximal withdrawal was usually $\sim 6 \mathrm{~mm}$ ). On each trial, we measured the siphon withdrawal, the spikes in the LE siphon sensory neuron, and the spikes or complex PSP in the LFS siphon motor neuron in response to the siphon stimulation. In some experiments, we also fired an action potential in the LE neuron with intracellular current injection through a bridge-balance circuit and measured the monosynaptic PSP produced in the motor neuron. The amplitudes and areas of the PSPs were measured using a laboratory interface to a microcomputer and commercially available software (Hilal Associates, Englewood, NJ). The data on dishabituation and sensitization were analyzed with one, two, or three-way ANOVA with one repeated measure (trial), followed by planned comparisons of the experimental group to the appropriate pre-shock and no-shock controls on each trial.
A

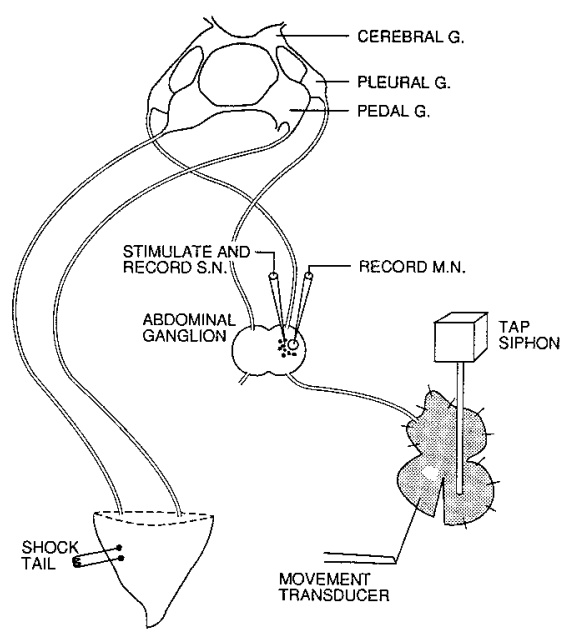

B
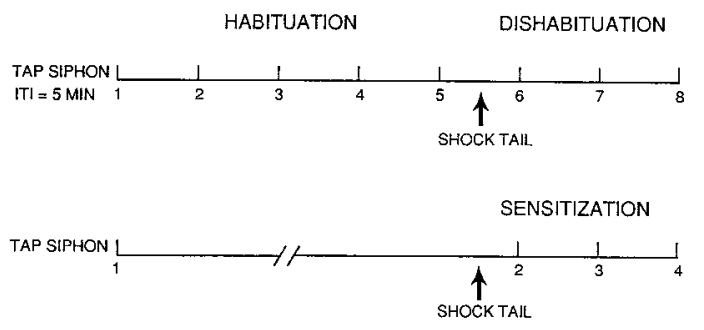

Figure 1. Experimental preparation $(A)$ and behavioral protocols $(B)$. See Materials and Methods for details.

\section{RESULTS}

\section{Contribution of the CNS to the reflex}

The siphon-elicited siphon withdrawal reflex is mediated in part by central motor neurons in the abdominal ganglion and in part by peripheral motor neurons in the siphon itself (Perlman, 1979). Both types of motor neurons receive monosynaptic input from the LE siphon sensory neurons (Bailey et al., 1979). To estimate the relative contributions of the central and peripheral components of the reflex, we compared the reflex response before and after cutting the siphon nerve, which connects the siphon to the abdominal ganglion (Fig. 1A). To measure the baseline level we first recorded the response during five trials of siphon stimulation, which produced approximately equal habituation in two groups of preparations (Fig. 2). We then cut the siphon nerve in one group, waited $1 \mathrm{hr}$ for recovery, and gave five more trials of siphon stimulation. In the control (uncut) group, the siphon reflex recovered completely on trial 6 after the $1 \mathrm{hr}$ rest (107.6 $\pm 13.4 \%$ of trial $1, n=9$ ). By contrast, in the experimental (cut) group, the amplitude of the response on trial 6 was only $\sim 45 \%$ of the response on trial $1(44.1 \pm 9.3 \%, n=11)$. We obtained similar results when we compared the average responses on trials 6-10 with trials $1-5$ (control, $96.7 \pm 8.3 \%$; cut, $47.9 \pm 8.2 \%$ ). These results indicate that $\sim 55 \%$ of the reflex is mediated through the CNS, which agrees very well with the estimate of $55 \%$ by Perlman (1979). When we looked at the area (instead of the amplitude) of the response, the withdrawal on trial 6 was slightly smaller in the cut group (31.9 $\pm 4.7 \%$ of trial 1$)$, suggesting that the CNS may contribute to the duration as well as the amplitude of the reflex. 
A1

Control
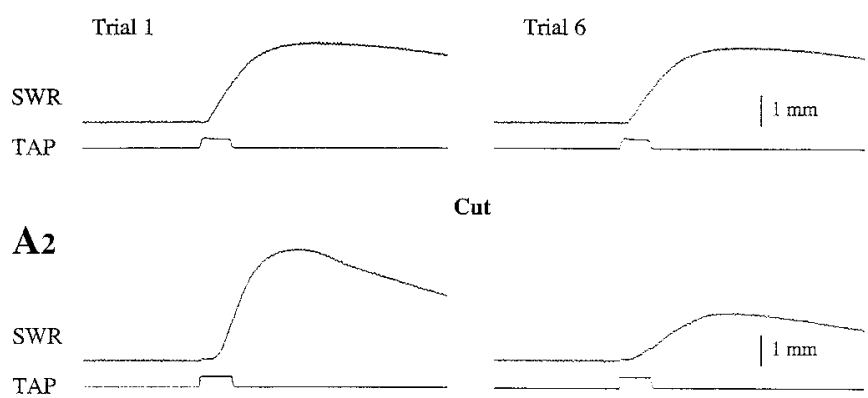

Cut

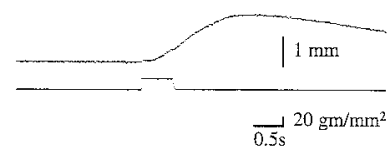

B

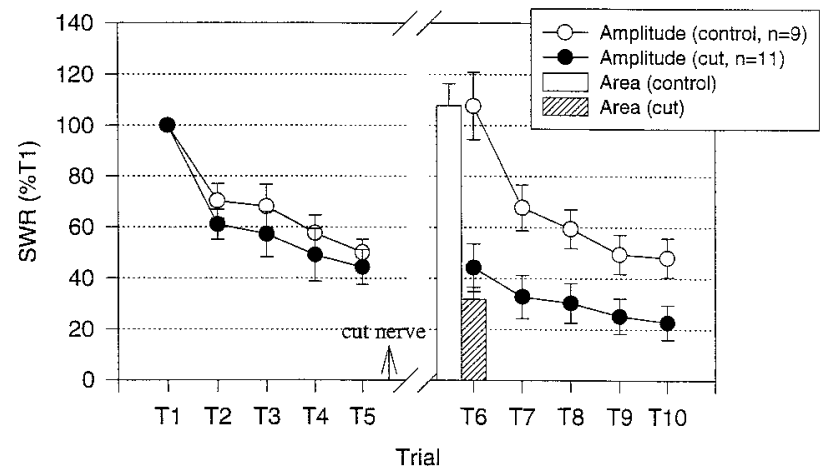

Figure 2. Contribution of the CNS to the siphon withdrawal reflex. $A$, Records from representative experiments showing the siphon-withdrawal reflex $(S W R)$ in response to a siphon tap $(T A P)$ on trials 1 and 6 in a control preparation $\left(A_{1}\right)$ and a preparation in which the siphon nerve was cut between trials 5 and $6\left(A_{2}\right)$. B, Average amplitude of siphon withdrawal in two groups of preparations, both of which received five trials of siphon stimulation with a $5 \mathrm{~min}$ interstimulus interval, a $1 \mathrm{hr}$ rest, and then five more trials of siphon stimulation. The siphon nerve was cut immediately after trial 5 in one group $(\mathrm{Cut})$. The average area of siphon withdrawal (measured during the first $1 \mathrm{sec}$ after the start of the withdrawal) is also shown for trial 6 (bars). The points show the means, and the error bars show the SEM. The data have been normalized to the value on trial 1 for each preparation [average amplitude on trial $1=1.8 \pm 0.4$ $\mathrm{mm}($ Control $)$ and $2.0 \pm 0.3 \mathrm{~mm}(\mathrm{Cut})$, average area $=2295 \pm 559 \mathrm{~mm} \times$ msec (Control) and $2049 \pm 367 \mathrm{~mm} \times \mathrm{msec}($ Cut $)$, not significantly different).

\section{Contribution of LFS $_{\mathrm{B}}$ siphon motor neurons to the reflex}

The central component of the siphon withdrawal reflex is mediated by five types of identified motor neurons in the abdominal ganglion ( $\mathrm{LFS}_{\mathrm{A}}, \mathrm{LFS}_{\mathrm{B}}, \mathrm{LBS}, \mathrm{LDS}$, and RDS), each of which produces a different type of siphon movement (Perlman 1979; Frost et al., 1988; Frost and Kandel, 1995; Hickie and Walters, 1995). At the beginning of each experiment, we searched for a motor neuron which, when fired with intracellular current injection, produced movement of the siphon that was measurable with our recording system. These were predominantly $\mathrm{LFS}_{\mathrm{B}}$ motor neurons, which receive strong excitatory input from tail stimulation and produce backward bending or "flaring" of the siphon in intact animals. By contrast, intracellular stimulation of either $\mathrm{LFS}_{\mathrm{A}}$ or LBS motor neurons produced only a very weak response with our recording system.

We estimated the contribution of a single motor neuron to the reflex response in our preparation in two ways. First, we measured the response alternately with and without that neuron
A

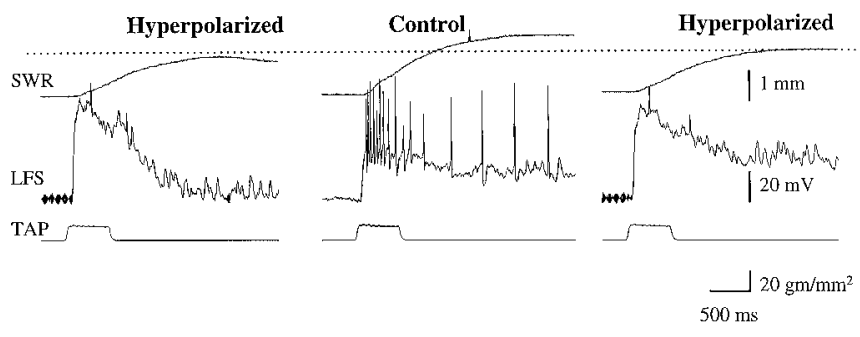

$\mathbf{B}_{1}$

TAP - SWR (ISI=1 min)

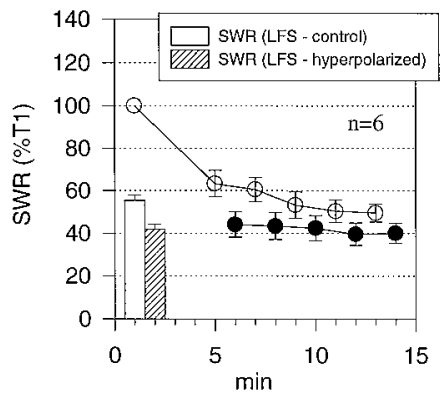

$\mathbf{B}_{2}$

TAP - SWR (ISI=20 min)

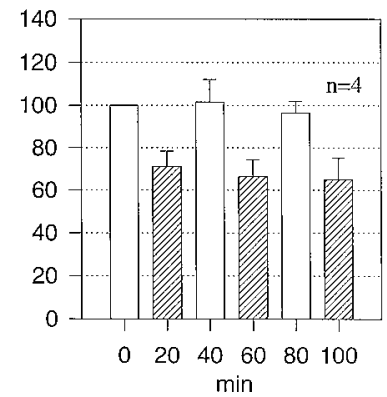

Figure 3. Contribution of a single $\mathrm{LFS}_{\mathrm{B}}$ siphon motor neuron to the siphon withdrawal reflex. $A$, Records from a representative experiment showing the siphon withdrawal in response to a siphon tap with an $\mathrm{LFS}_{\mathrm{B}}$ neuron alternately at resting potential (Control) or hyperpolarized to prevent it from spiking. $B$, Average amplitude of siphon withdrawal in two groups with interstimulus intervals of either $1 \mathrm{~min}\left(B_{7}\right)$ or $20 \mathrm{~min}\left(B_{2}\right)$. The bars in $B_{1}$ show the average withdrawal on the last five trials with the neuron either at resting potential or hyperpolarized. The average values on trial 1 (Control) were $2.9 \pm 0.4 \mathrm{~mm}\left(B_{1}\right)$ and $3.2 \pm 0.9 \mathrm{~mm}\left(B_{2}\right)$.

hyperpolarized by intracellular current injection, which prevents spiking and effectively removes the neuron from the circuit (Fig. 3). In a few experiments in which we recorded from two $\mathrm{LFS}_{\mathrm{B}}$ neurons simultaneously, we did not detect any evidence of electrical coupling between them. In two series of experiments with interstimulus intervals of either 1 or $20 \mathrm{~min}$, hyperpolarizing a single $\mathrm{LFS}_{\mathrm{B}}$ motor neuron reduced the reflex response $\sim 25$ or $30 \%(-25.1 \pm 3.4 \%, n=6$, with a $1 \mathrm{~min}$ ISI; $-32.5 \pm 5.9 \%, n=$ 4 , with a $20 \mathrm{~min}$ ISI).

As a second method of estimating the contribution of a single $\mathrm{LFS}_{\mathrm{B}}$ neuron to the reflex response, we compared the response produced by intracellular stimulation of the motor neuron with the response produced by mechanical stimulation of the siphon (Fig. 4). There was a significant correlation between the frequency of firing of the motor neuron and the amplitude of the evoked contraction with either intracellular stimulation $(r=0.93$, $n=25, p<0.01)$ or siphon stimulation $(r=0.96, n=17, p<$ $0.01)$. When intracellular current was used to fire the motor neuron in the physiological range $(10-20 \mathrm{~Hz})$, the siphon withdrawal produced was $24.3 \%$ of the withdrawal produced by siphon stimulation. This estimate agrees well with the estimate obtained by hyperpolarizing the motor neuron (Fig. 3) and suggests that a single $\mathrm{LFS}_{\mathrm{B}}$ motor neuron contributes $\sim 25 \%$ of the reflex response, which agrees fairly well with the estimate of $18 \%$ by Frost and Kandel (1995). Because the entire CNS was estimated to contribute $\sim 55 \%$ of the reflex response (Fig. 2), these results suggest that only two or perhaps three motor neurons 
A
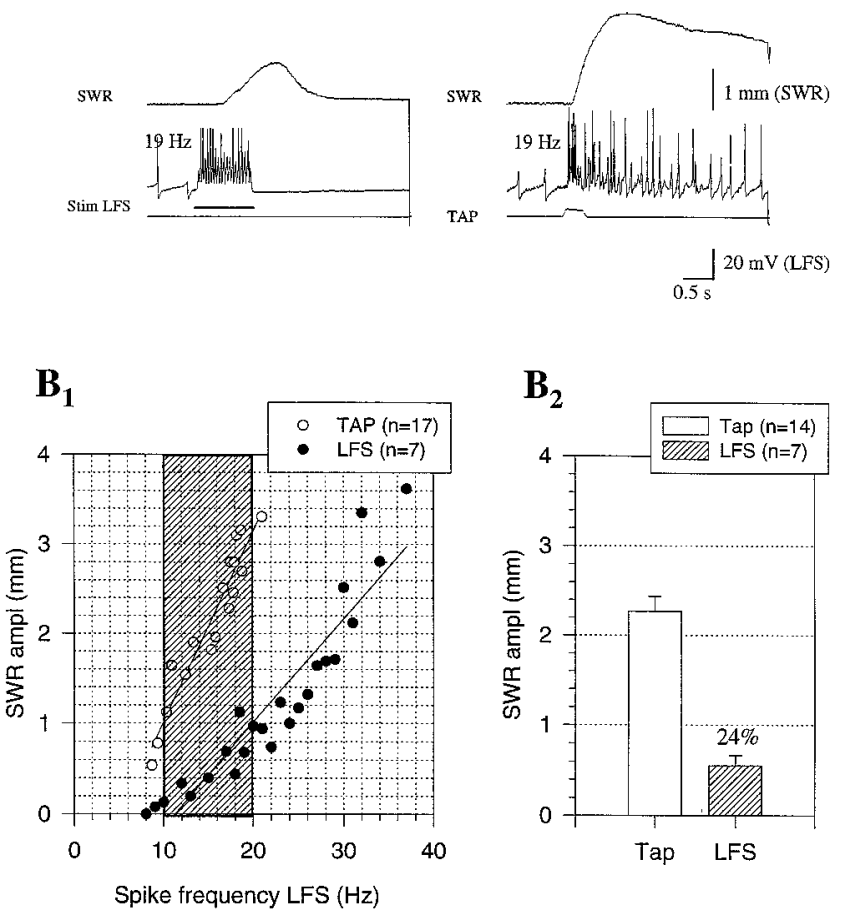

Figure 4. Comparison of siphon withdrawal produced by intracellular stimulation of a single $\mathrm{LFS}_{\mathrm{B}}$ siphon motor neuron and by a siphon tap. $A$, Records from a representative experiment showing the siphon withdrawal produced by intracellular current injection in an $\mathrm{LFS}_{\mathrm{B}}$ neuron (left) and a siphon tap (right). In both cases the $\mathrm{LFS}_{\mathrm{B}}$ neuron fired 19 spikes during the first $1 \mathrm{sec}$ after the start of firing. $B$, Group data from experiments like the one shown in $A . B_{1}$, Scatterplot of the amplitude of siphon withdrawal and the frequency of LFS firing in the first $1 \mathrm{sec}$ on trial 1 in 17 experiments with siphon taps $(\bigcirc)$ and on 25 trials in seven experiments with intracellular stimulation of an $\mathrm{LFS}_{\mathrm{B}}$ neuron $(\mathbf{)})$. The lines indicate the linear regressions. $B_{2}$, The average amplitude of siphon withdrawal produced by $\mathrm{LFS}_{\mathrm{B}}$ firing in the physiological range $(10-20 \mathrm{~Hz})$ in the two groups shown in $B_{1}$.

mediate most of the central component of the reflex measured with our recording system. This is slightly surprising because there are thought to be four $\mathrm{LFS}_{\mathrm{B}}$ neurons (Frost et al., 1988; Frost and Kandel, 1995; Hickie and Walters, 1995). However, even the four $\mathrm{LFS}_{\mathrm{B}}$ neurons produce somewhat different siphon movements (Hickie and Walters, 1995), not all of which may be measured equally with our recording system.

\section{Firing of LFS motor neurons and LE sensory neurons during habituation, dishabituation, and sensitization}

We next began an analysis of habituation, dishabituation, and sensitization of the reflex. As shown in the example in Figure 5 and the average results in Figure $6 \mathrm{~A}$, there was significant behavioral habituation of siphon withdrawal on trial 5, compared with trial 1, in two independent groups $\left(F_{(1,20)}=133.27, p<0.01\right)$. One group $(n=17)$, which received tail shock 2.5 min after trial 5 , showed significant dishabituation on trial $6,2.5$ min after the shock $\left(F_{(1,40)}=65.04, p<0.01\right)$, and on trial 7, 7.5 min after the shock $\left(F_{(1,40)}=16.65, p<0.01\right)$ compared with trial 5 . The shocked group also showed significant dishabituation compared with a no-shock control group $(n=5)$ on trials 6 and $7(p<0.05$ in each case). Similarly, another group that was not first habituated $(n=14)$ showed significant sensitization on trial 2, $2.5 \mathrm{~min}$ after the shock, compared with trial $1\left(F_{(1,32)}=23.79, p<0.01\right)$.
That group also showed significant sensitization compared with a no-shock control group $(n=4)$ on trial $2(p<0.05)$. For both dishabituation and sensitization, the effects were largest $2.5 \mathrm{~min}$ after the shock and had partially declined by $12.5 \mathrm{~min}$ after the shock. There was no significant difference between the amplitudes or time courses of dishabituation and sensitization $\left(F_{(1,36)}\right.$ $=0.01$ for the interaction of group and shock).

In these experiments we recorded the firing of an LFS motor neuron and in most cases also an LE sensory neuron simultaneously with the siphon withdrawal. Figure 5 shows examples of the neuronal activity, and Figure $6 B$ shows the average evoked firing during the first $1 \mathrm{sec}$ after the start of the response to siphon stimulation, which included the peak of the siphon withdrawal on most trials (the average time-to-peak of siphon withdrawal was $731 \pm 23 \mathrm{msec}$ overall and did not change by $>170 \mathrm{msec}$ during habituation, dishabituation, or sensitization). There was a significant decrease in evoked firing of the motor neuron on trial 5, compared with trial 1, in both habituation groups $\left(F_{(1,20)}=\right.$ $289.92, p<0.01$ ), which correlated significantly with the decrease in siphon withdrawal $(r=0.35, p<0.05$, one-tail comparing the decreases in LFS spikes and siphon withdrawal). This correlation was more modest than in similar studies on other preparations (Cohen et al., 1997), perhaps because a single central motor neuron contributes only $\sim 25 \%$ of the siphon withdrawal response. During dishabituation, there was a significant increase in evoked firing of the motor neuron on trials 6,7 , and 8 , compared with trial $5(p<0.01$ in each case), which correlated significantly with the increase in siphon withdrawal on each trial $(r=0.45, p<$ 0.05 on trial 6). The dishabituation group also showed a significant increase in evoked firing of the motor neuron compared with the no-shock control group on each trial after the shock $(p<0.05$ in each case). Similarly, during sensitization, there was a significant increase in evoked firing of the motor neuron on trial 2 , compared with trial $1\left(F_{(1,32)}=25.66, p<0.01\right)$, which correlated significantly with the increase in siphon withdrawal $(r=0.45, p<$ 0.05 , one-tail). The sensitization group also showed a significant increase in evoked firing of the motor neuron compared with the no-shock control group on trials 2 and 3 ( $p<0.05$ in each case). For both dishabituation and sensitization, the increases in evoked firing of the motor neuron were largest $2.5 \mathrm{~min}$ after the shock and had partially declined by $12.5 \mathrm{~min}$ after the shock. There was no significant difference between the amplitudes or time courses of the increases during dishabituation and sensitization $\left(F_{(1,36)}=\right.$ 0.03 for the interaction of group and shock).

When the siphon tap was within the receptive field of an LE sensory neuron ("on-field"), it always caused the LE neuron to fire action potentials. Unlike the LFS motor neurons, evoked firing of the LE sensory neurons did not change significantly during habituation, dishabituation $(n=10)$, or sensitization $(n=$ 9 ), although there were small and nonsignificant trends for a decrease in firing of the LE neurons during habituation and an increase during dishabituation and sensitization (Fig. $6 C$, and see Fig. 15). Sensitizing stimuli have been shown to produce a much larger increase in evoked firing of the Aplysia tail sensory neurons (Walters et al., 1983), and repeated sensitizing stimuli can also produce a larger increase in firing of the LE neurons (our unpublished observations).

These results suggest that habituation, dishabituation, and sensitization of siphon withdrawal are attributable at least in part to changes in evoked firing of the LFS motor neurons. These changes cannot be explained by alterations in firing of the LE sensory neurons, and therefore could involve changes in synaptic 
A

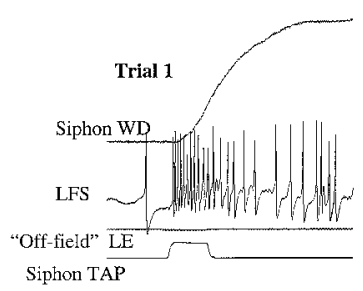

B

Figure 5. Records from representative experiments showing the siphon withdrawal and the firing of an $\mathrm{LFS}_{\mathrm{B}}$ siphon motor neuron and an LE siphon sensory neuron in response to siphon stimulation during habituation, dishabituation, and sensitization (see Fig. $1 B$ for the behavioral protocols).
Habituation

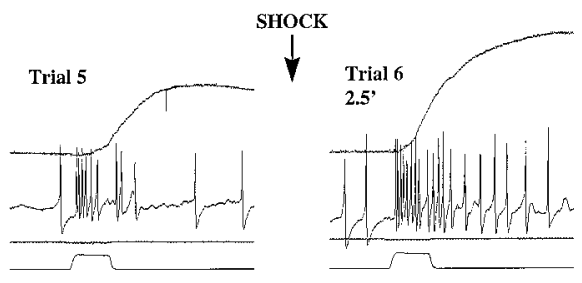

Dishabituation

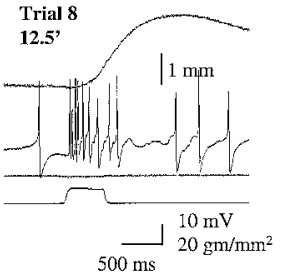

transmission in the CNS. Moreover, during habituation, the percentage change in siphon withdrawal was approximately the same as the percentage change in evoked firing of LFS motor neurons, but during dishabituation and sensitization the percentage change in siphon withdrawal was larger than the change in evoked firing of the motor neurons (see Fig. 15). These results suggest that additional mechanisms may also contribute to dishabituation and sensitization.

One possible additional mechanism is a change in the pattern of firing of the LFS motor neurons, such that the same number of spikes produced greater siphon withdrawal. As shown in the examples in Figure 5 and the average results in Figure 7, the evoked firing of LFS motor neurons on each trial tended to follow a reproducible pattern with four components that have previously been described for the gill motor neuron LDG1 (Cohen et al., 1997): an initial high-frequency burst, a sustained response during the tap, a smaller second burst around the offset of the tap, and a gradual decline in firing after the tap. The pattern of firing of the LE sensory neurons was also similar to that described previously (Byrne et al., 1974; Frost et al., 1997) and matched the first two components of the pattern of firing of the LFS neurons: an initial high-frequency burst and a sustained response during the tap, but little firing after the tap. These results suggest that the LE neurons contribute directly to firing of the LFS neurons during the tap but contribute only indirectly to LFS firing after the tap.

There was no significant change in the pattern of firing of the LE neurons during habituation, dishabituation, or sensitization. There was a small but significant change in the pattern of firing of the LFS neurons during habituation $\left(F_{(14,224)}=2.04, p<0.05\right.$ for the effect of bin), with the biggest decreases in firing occurring near the onset of the tap (in the first three bins or $150 \mathrm{msec}$ ). However, there was no significant change in the pattern of firing of the LFS neurons during dishabituation or sensitization that could contribute to changes in siphon withdrawal during those forms of learning.

Another possible mechanism that could contribute to enhanced siphon withdrawal during dishabituation and sensitization is peripheral enhancement, perhaps attributable to post-tetanic potentiation (PTP) at the neuromuscular junction. Frost et al. (1988) provided evidence that PTP at the neuromuscular junction of LFS neurons contributed to sensitization of the siphonwithdrawal reflex in similar experiments. Consistent with that possibility, there were changes in spontaneous as well as evoked firing of LFS neurons during dishabituation and sensitization in our experiments (Fig. 6C). During dishabituation, there was a significant increase in spontaneous firing measured just before trial 6, $2.5 \mathrm{~min}$ after the shock $\left(F_{(1,32)}=50.85, p<0.01\right)$, and trial 7, 7.5 min after the shock $\left(F_{(1,32)}=5.31, p<0.05\right)$. Similarly, during sensitization, there was a significant increase in spontaneous firing on trial 2, 2.5 min after the shock $\left(F_{(1,26)}=53.20, p<\right.$ $0.01)$, and trial 3, 7.5 min after the shock $\left(F_{(1,26)}=4.89, p<0.05\right)$. These changes in spontaneous firing might give rise to peripheral enhancement 2.5 and 7.5 min after the shock.

\section{Peripheral enhancement contributes to dishabituation and sensitization}

We tested peripheral enhancement by measuring the siphon withdrawal produced by intracellular stimulation of an LFS neuron with a dishabituation design (Fig. 8). There was no significant change in the siphon withdrawal produced by LFS stimulation on trial 5 compared with trail 1, indicating that peripheral depression or fatigue make little contribution to habituation. By contrast, there was a modest $(\sim 10 \%)$ but significant increase in siphon withdrawal on trial 6, 2.5 min after the shock $\left(F_{(1,12)}=15.22, p<\right.$ $0.01)$, that had worn off by trial 7, 7.5 min after the shock. These results suggest that peripheral enhancement makes some contribution to dishabituation and sensitization $2.5 \mathrm{~min}$ after the shock, in agreement with previous studies on other preparations (Jacklet and Rine, 1977; Cohen et al., 1997).

As shown in Figure 8, there was no significant change in the number of spikes produced in the LFS neuron by constant current injection. This result indicates that the excitability of the LFS neuron remained relatively constant after the tail shock, and therefore that changes in the number of spikes produced by siphon stimulation during dishabituation and sensitization (Figs. $5,6 B$ ) were attributable to changes in synaptic input to the motor neuron. 
A
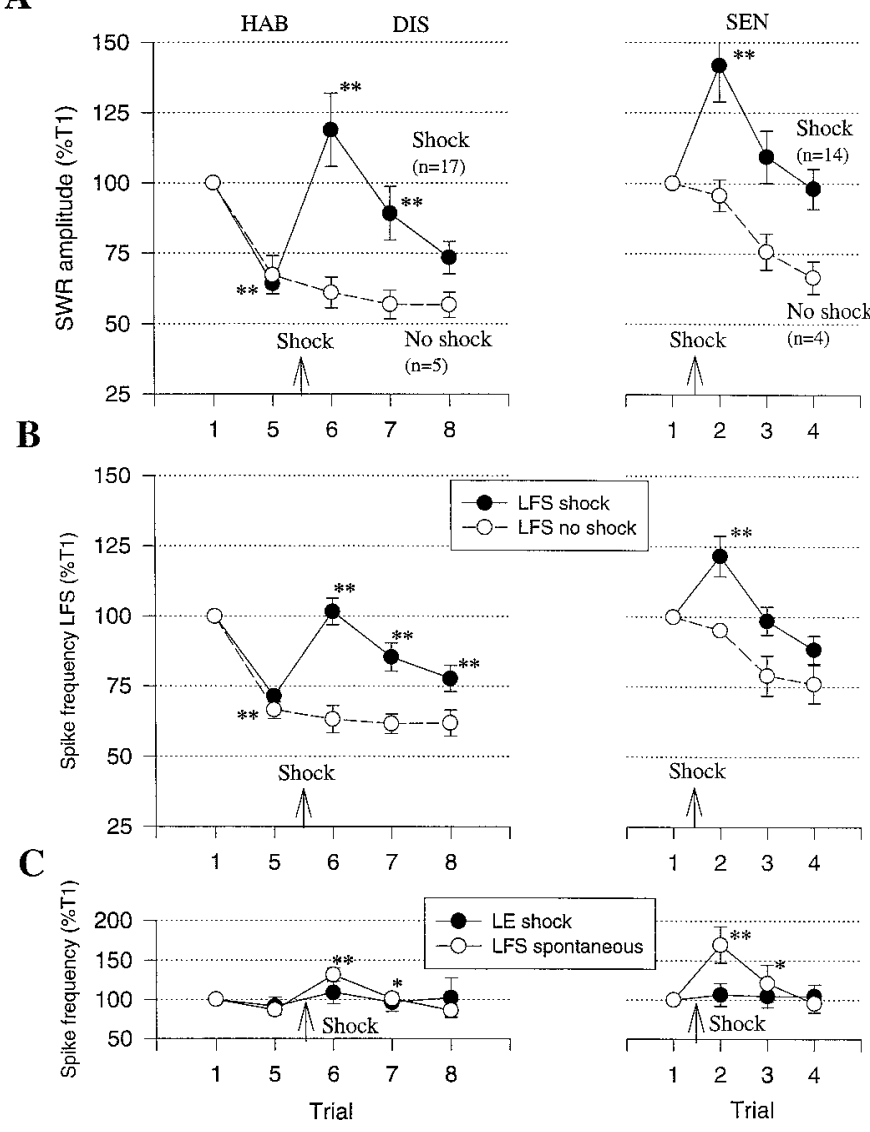

Figure 6. The average siphon withdrawal and firing of $\mathrm{LFS}_{\mathrm{B}}$ motor neurons and LE sensory neurons during habituation $(H A B)$ and dishabituation $(D I S)$ in experiments like the one shown in Figure $5 A$ and during sensitization $(S E N)$ in experiments like the one shown in Figure $5 B . A$, The average amplitude of siphon withdrawal in response to siphon stimulation in the group receiving tail shock $(\bullet)$ and in a no-shock control group $(\bigcirc) .{ }^{*} p<0.05,{ }^{* *} p<0.01$ compared with trial 1 for habituation and sensitization, and compared with trial 5 for dishabituation. The average values on trial 1 were $2.1 \pm 0.2 \mathrm{~mm}$ (DIS, Shock), $2.4 \pm 0.3 \mathrm{~mm}(D I S, N o$ shock), $2.3 \pm 0.3 \mathrm{~mm}$ (SEN, Shock), and $2.1 \pm 0.2 \mathrm{~mm}$ (SEN, No shock); not significantly different. $B$, The average frequency of firing of $\mathrm{LFS}_{\mathrm{B}}$ neurons during the first $1 \mathrm{sec}$ after the start of firing measured simultaneously with the siphon withdrawals shown in $A$. The average values on trial 1 were $15.8 \pm 0.9 \mathrm{~Hz}$ (DIS, Shock), $15.8 \pm 1.2 \mathrm{~Hz}$ (DIS, No shock), $15.6 \pm 0.9 \mathrm{~Hz}(S E N$, Shock), and $15.0 \pm 1.1 \mathrm{~Hz}$ (SEN, No shock); not significantly different. $C$, The average frequency of firing of LE neurons during the first $1 \mathrm{sec}$ after the start of firing (0) and the average spontaneous firing of LFS neurons during the $5 \mathrm{sec}$ before each siphon stimulation. The average values on trial 1 were $3.5 \pm 0.7 \mathrm{~Hz}(L E, D I S), 3.1 \pm 0.6$ $\mathrm{Hz}(L E, S E N), 1.2 \pm 0.1 \mathrm{~Hz}(L F S, D I S)$, and $1.0 \pm 0.1 \mathrm{~Hz}(L F S, S E N)$.

\section{Plasticity of the complex PSP in an LFS neuron during habituation, dishabituation, and sensitization}

We directly tested the possibility that habituation, dishabituation, and sensitization involve changes in the synaptic input to LFS motor neurons by hyperpolarizing the motor neuron during the siphon tap, preventing it from firing, and allowing measurement of the underlying complex PSP. In these experiments, we also measured the remaining siphon withdrawal with the LFS motor neuron hyperpolarized and found that although the overall amplitude of the reflex was reduced, its plasticity during habituation, dishabituation, and sensitization was normal (Figs. 9, 10A). This result suggests that firing of the remaining motor neurons under- went plasticity similar to that of the neuron that was hyperpolarized.

As shown in the examples in Figure 9 and the average results in Figure 11, the complex PSP in an LFS neuron had a complicated shape with the same four components that were described previously for evoked spikes: an initial peak near the onset of the tap, a smaller sustained depolarization during the tap, a second peak around the offset of the tap, and a gradual decline after the tap. We therefore measured the total area under the PSP in the first 1 sec rather than simply measuring peak amplitude (Fig. 10B). During habituation, there was a significant decrease in the area of the PSP on trial 5, compared with trial 1, in two independent groups $\left(F_{(1,14)}=78.91, p<0.01\right)$. During dishabituation, there was a significant increase in the area of the PSP on each trial after the shock $(6,7$, and 8) compared with either trial 5 or the no-shock control group ( $p<0.01$ in each case). Similarly, during sensitization there was a significant increase in the area of the PSP on the first two trials after the shock ( 2 and 3 ) compared with either trial 1 or a no-shock control group ( $p<0.01$ in each case). For both dishabituation and sensitization, the increases in the area of the complex PSP were largest 2.5 min after the shock and had partially declined by 12.5 min after the shock. There was no significant difference between the amplitudes or time courses of the increases during dishabituation and sensitization $\left(F_{(1,27)}=\right.$ 1.28 for the interaction of group and shock).

These results are very similar to results on evoked firing of the motor neuron (Fig. 6B) and suggest that changes in the complex PSP can largely account for changes in evoked firing. However, there were some more subtle differences between evoked firing and the complex PSP, and also between dishabituation and sensitization, when we examined changes in the shape of the response (Fig. 11). Unlike evoked firing (Fig. 7), there was no significant change in the shape of the complex PSP during habituation. There was also no significant change during dishabituation. However, there was a small but significant change in the shape of the complex PSP during sensitization $\left(F_{(29,261)}=2.31\right.$, $p<0.01$ for the effect of bin), with the biggest increase in the amplitude of the PSP occurring around the offset of the tap (in bins 7-12, during the end of the sustained depolarization during the tap and the beginning of the second peak after the offset of the tap). Moreover, the change in the shape of the complex PSP was significantly different during sensitization than during dishabituation $\left(F_{(29,551)}=2.01, p<0.01\right.$ for the interaction of group and bin).

\section{Contribution of monosynaptic PSPs from LE sensory neurons to the complex PSP in LFS motor neurons}

The complex PSP in an LFS motor neuron includes a direct contribution from sensory neurons and an indirect contribution via interneurons, several of which have been identified (Frost and Kandel, 1995). To estimate the direct contribution of LE sensory neurons, we compared the monosynaptic PSP produced in a motor neuron by intracellular stimulation of an LE sensory neuron and the complex PSP produced by mechanical stimulation of the siphon, measured $\sim 10 \mathrm{sec}$ apart under identical conditions (Fig. 12). On average, the amplitude of the monosynaptic PSP produced by a single spike in an LE cell was $29.1 \pm 2.4 \%$ of the amplitude of the complex PSP, and the area of the monosynaptic PSP was $3.6 \pm 0.2 \%$ of the area of the complex PSP $(n=21)$. When the tap was within the receptive field of the LE cell, it fired 
$\mathbf{A}_{1}$

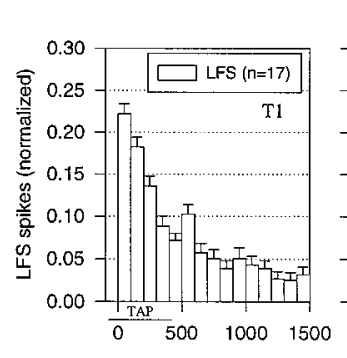

$\mathbf{A}_{2}$
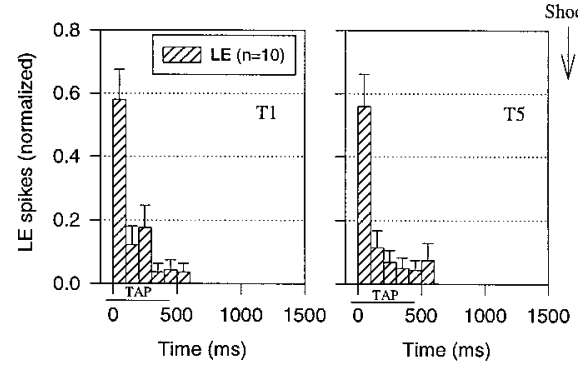

$\mathbf{B}_{1}$
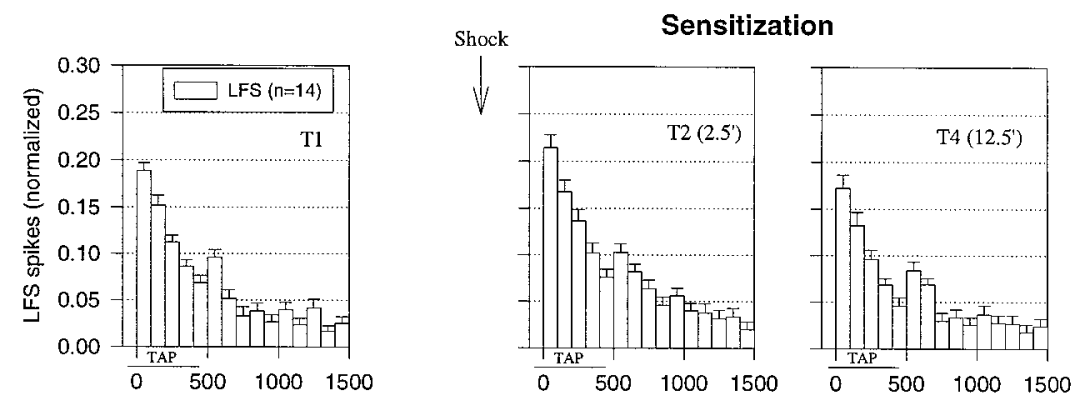

Figure 7. The average pattern of firing of LFS motor neurons and LE sensory neurons during habituation, dishabituation, and sensitization of siphon withdrawal in the same experiments as Figure 6. A, Firing of LFS $\left(A_{1}\right)$ and LE $\left(A_{2}\right)$ neurons during habituation and dishabituation. $B$, Firing of LFS $\left(B_{1}\right)$ and LE $\left(B_{2}\right)$ neurons during sensitization. On each trial, the number of spikes in each $100 \mathrm{msec}$ interval has been normalized to the total number of spikes on trial 1 in each experiment (average on trial $1=18.2 \pm 0.9$ in $\mathrm{A}_{1}, 3.5 \pm 0.7$ in $A_{2}, 18.4 \pm 1.2$ in $\mathrm{B}_{1}$, and $3.1 \pm 0.6$ in $B_{2}$ ). The horizontal bar below the $x$-axis indicates the duration of the siphon tap.
$\mathbf{B}_{2}$

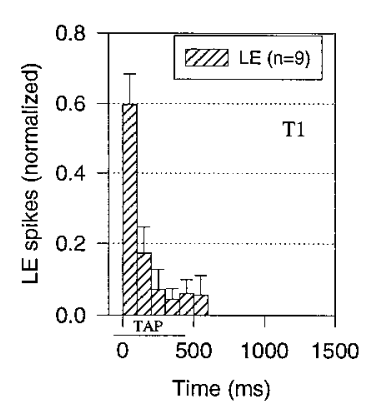

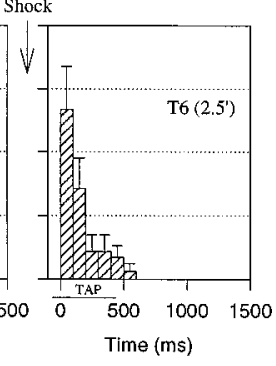
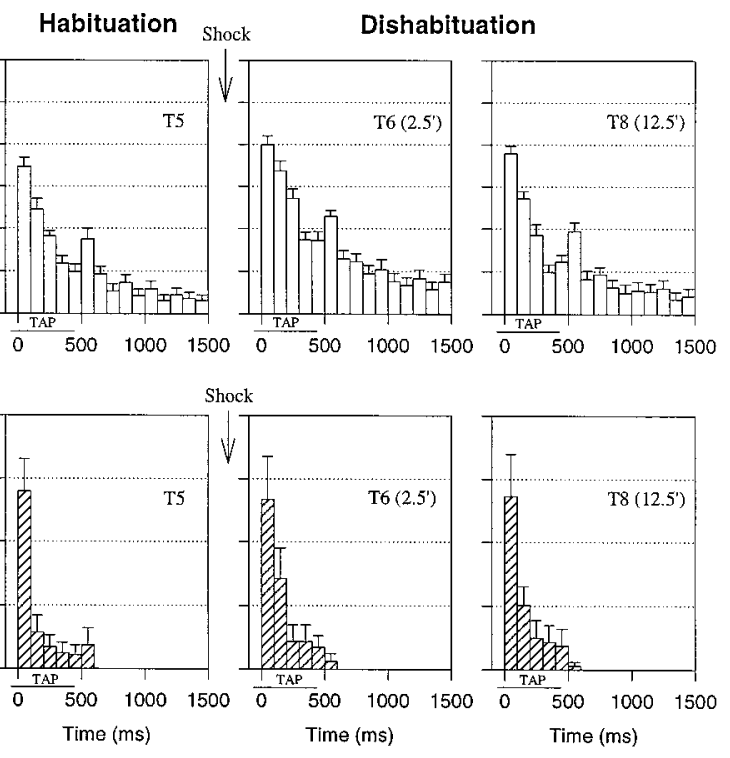

Time $(\mathrm{ms})$

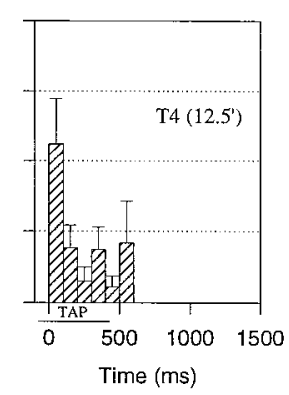

on average $3.3 \pm 0.5$ spikes during the tap $(n=19)$. Taps of this strength are thought to activate approximately five LE cells (Byrne et al., 1974; Hickie et al., 1997). Multiplying these numbers suggests that monosynaptic PSPs from the LE cells would contribute $\sim 60 \%$ of the area of the complex PSP if they added linearly. Previous estimates of the average monosynaptic contribution based on different methods have ranged from 5\% (Hickie et al., 1997), 25\% (Trudeau and Castellucci, 1992; Cohen et al., 1997), to $>50 \%$ (Byrne et al., 1978; Frost et al., 1997). Some of the differences in results may be explained by differences in the siphon stimulation, because very weak, brief stimuli are able to elicit a withdrawal reflex without activating the LE cells at all, presumably by activating an as yet unidentified class of sensory neurons with a lower threshold but otherwise similar properties (Frost et al., 1997).

\section{Plasticity of the monosynaptic PSPs from LE neurons during habituation, dishabituation, and sensitization}

To examine plasticity of the monosynaptic PSPs, we tested the PSP from an LE neuron to the motor neuron $10 \mathrm{sec}$ before the first and fifth trials of habituation training, and before trials 6, 7, and 8 of dishabituation and trials $1-4$ of sensitization. As shown in the examples in Figure 13 and the average results in Figure 14, when the siphon tap was within the receptive field of an LE cell and caused it to fire action potentials (on-field), the amplitude of the monosynaptic PSP from that LE cell underwent significant depression during habituation training in two independent groups $\left(-39.5 \pm 4.4 \%, n=15 ; F_{(1,21)}=78.43, p<0.01\right.$ compared with trial 1). By contrast, when the siphon tap was outside the receptive field of an LE cell and did not cause it to fire (off-field), 

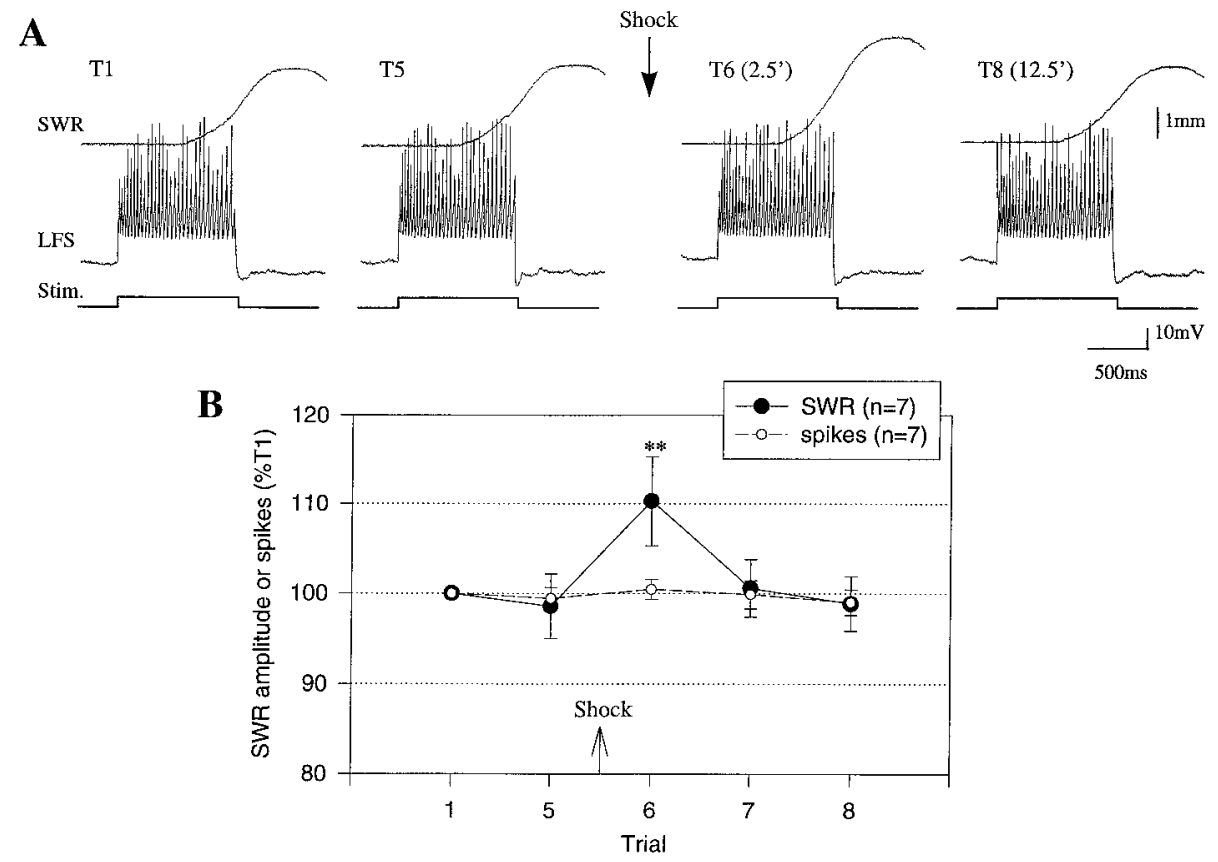

Figure 8. Siphon withdrawal produced by intracellular stimulation of an $\mathrm{LFS}_{\mathrm{B}}$ neuron before and after tail shock. $A$, Records from a representative experiment showing the siphon withdrawal produced by firing an $\mathrm{LFS}_{\mathrm{B}}$ neuron with intracellular current injection. The $\mathrm{LFS}_{\mathrm{B}}$ neuron was stimulated on eight trials with an intertrial interval of $5 \mathrm{~min}$, and the tail was shocked 2.5 min before trial 6. $B$, Average amplitude of siphon withdrawal $(\bullet)$ and LFS spike frequency $(\bigcirc)$ in experiments like the one shown in $A$. The average values on trial 1 were $1.5 \pm 0.3 \mathrm{~mm}$ $(S W R)$ and $24.0 \pm 2.1 \mathrm{~mm}$ (LFS spikes).
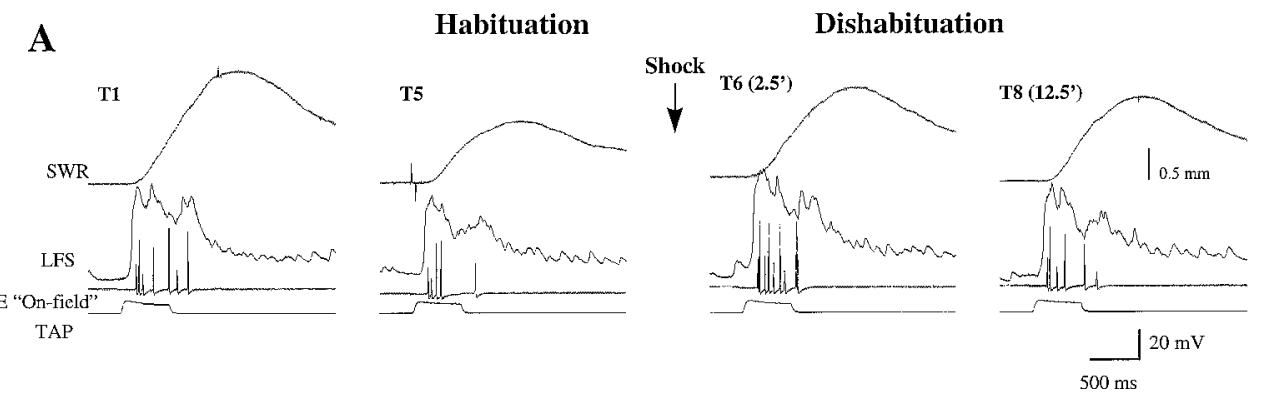

\section{B}
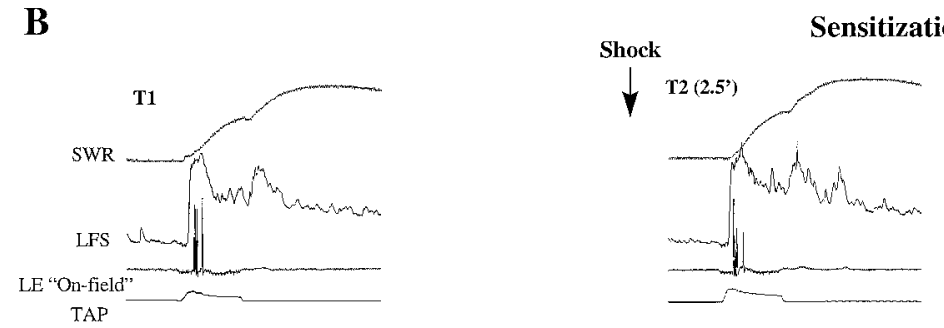

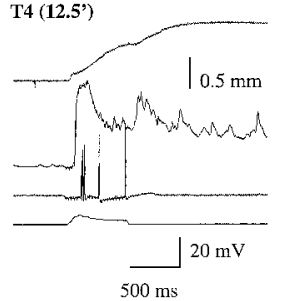

Figure 9. Records from representative experiments showing the complex PSP produced in an $\mathrm{LFS}_{\mathrm{B}}$ neuron by siphon stimulation during habituation, dishabituation $(A)$, and sensitization $(B)$. The LFS neuron was hyperpolarized to keep it from firing during each siphon tap. the monosynaptic PSP did not undergo depression $(-3.6 \pm 5.6 \%$, $n=5 ; F_{(1,21)}=24.34, p<0.01$ compared with on-field). Results were similar when we measured the area of the monosynaptic PSP [which is more directly comparable to the area of the complex PSP (Fig. 15)] instead of its amplitude [which can be measured more accurately when the PSP includes a late polysynaptic component (Fig. 13B)]. These results are similar to the results of previous studies (Frost et al., 1997) and are consistent with the idea that habituation involves homosynaptic depression of sensory neuron PSPs attributable to firing of the sensory neurons during the siphon stimulation (Castellucci et al., 1970; Kupfermann et al., 1970; Byrne et al., 1978). Depression of the monosynaptic PSPs was of sufficient amplitude and duration to account for most or all of the behavioral habituation in these experiments, although other mechanisms may also contribute under some circumstances (Goldberg and Lukowiak, 1984; Stopfer and Carew, 1996; Frost et al., 1997).

We then went on to conduct similar studies of dishabituation and sensitization. During dishabituation training, there was significant facilitation of monosynaptic PSPs from on-field sensory neurons on the first trial after the shock (trial 6) compared with either trial $5\left(F_{(1,42)}=64.04, p<0.01\right)$ or a no-shock control group $\left(F_{(1,42)}=26.70, p<0.01\right)$. Unlike habituation training, during which depression was restricted to PSPs from on-field sensory neurons, during dishabituation training there was also significant facilitation of monosynaptic PSPs from off-field sensory neurons on trial 6 , compared with trial $5\left(F_{(1,42)}=20.66, p<\right.$ $0.01)$. Similarly, during sensitization training there was significant facilitation of monosynaptic PSPs from either on-field or off-field sensory neurons on the first trial after the shock (trial 2) com- 
A

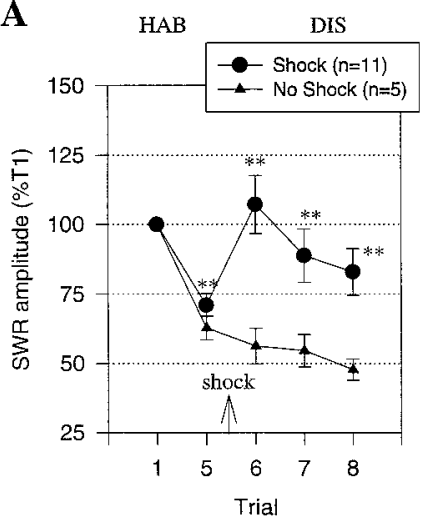

B

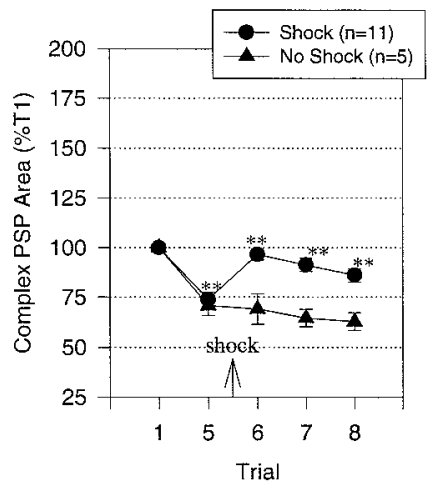

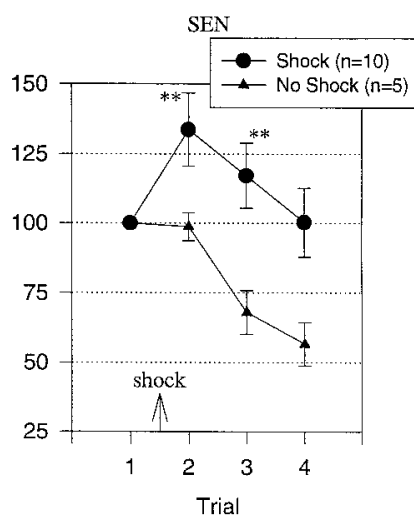

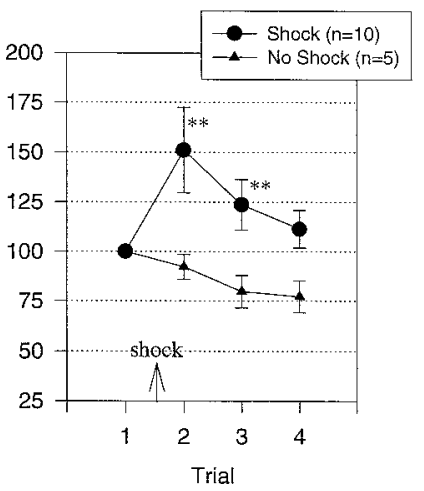

Figure 10. The average siphon withdrawal and area of the complex PSP in an $\mathrm{LFS}_{\mathrm{B}}$ neuron during habituation, dishabituation, and sensitization in experiments like the ones shown in Figure 9. $A$, The amplitude of siphon withdrawal in response to siphon stimulation in experiments in which an $\mathrm{LFS}_{\mathrm{B}}$ motor neuron was hyperpolarized and therefore did not contribute to the withdrawal response. The average values on trial 1 were $1.7 \pm 0.2 \mathrm{~mm}$ (DIS, Shock), $1.1 \pm 0.3 \mathrm{~mm}(D I S$, No shock), $1.6 \pm 0.2 \mathrm{~mm}$ (SEN, Shock), and $1.0 \pm 0.2 \mathrm{~mm}$ (SEN, No shock). B, The average area of the complex PSP in the hyperpolarized $\mathrm{LFS}_{\mathrm{B}}$ neuron measured simultaneously with the siphon withdrawals shown in $A$. PSP area was measured during the first $1 \mathrm{sec}$ after the start of the PSP and normalized to the area on trial 1 in each experiment (average on trial $1=38,217 \pm 3835 \mathrm{mV} \times$ msec for DIS, Shock, 41,904 $\pm 5389 \mathrm{mV} \times$ msec for DIS, No shock, $40,171 \pm 4125 \mathrm{mV} \times \mathrm{msec}$ for $S E N$, Shock, and 48,330 $\pm 5430 \mathrm{mV} \times \mathrm{msec}$ for $S E N$, No shock, not significantly different).

pared with either trial 1 ( $p<0.01$ in each case) or a no-shock control group $(p<0.05)$. During both dishabituation and sensitization training, facilitation of the monosynaptic PSP was largest $2.5 \mathrm{~min}$ after the shock and had partially declined by $12.5 \mathrm{~min}$ after the shock. There was no significant difference between the amplitudes or time courses of facilitation of on-field PSPs during dishabituation and sensitization $\left(F_{(1,24)}=0.76\right.$ for the interaction of group and shock). These results are consistent with the idea that dishabituation and sensitization involve heterosynaptic facilitation of sensory neuron PSPs attributable to firing of facilitator interneurons during the tail shock (Castellucci et al., 1970; Kupfermann et al., 1970; Walters et al., 1983; Mackey et al., 1989; Wright et al., 1991; Trudeau and Castellucci, 1993). Moreover, the observation that facilitation of the monosynaptic PSPs was approximately the same during dishabituation as during sensitization suggests that dishabituation involves the same basic mechanism as sensitization (heterosynaptic facilitation) superimposed on homosynaptic depression. Carew et al. (1971) came to similar conclusions based on an analysis of complex PSPs during neural analogs of dishabituation and sensitization.

Plasticity of the on-field monosynaptic PSPs was approximately equal to plasticity of the complex PSPs and firing of the LFS motor neurons during habituation, dishabituation, and sensitization (Fig. 15). Plasticity of LFS firing was in turn approximately equal to plasticity of the behavior during habituation. However, during dishabituation and sensitization, the increase in siphon withdrawal was somewhat larger than the increase in LFS firing, in part because of peripheral enhancement (Fig. 8). Thus, these three mechanisms (homosynaptic depression and heterosynaptic facilitation of monosynaptic PSPs, and peripheral enhancement) appear to be sufficient to explain most of the changes in siphon withdrawal during habituation, dishabituation, and sensitization.

\section{DISCUSSION}

To try to test the relationship between synaptic plasticity and learning and memory in a more rigorous fashion than was previously possible, Cohen et al. (1997) first developed a simplified gill-withdrawal preparation in which most of the reflex response is mediated through a single identified motor neuron. Frost et al. (1997) then used that preparation to provide direct evidence that homosynaptic depression of monosynaptic PSPs from LE siphon sensory neurons contributes to habituation of the reflex response. However, it was difficult to record monosynaptic PSPs during dishabituation and sensitization in the gill-withdrawal preparation. We therefore developed the simplified siphon-withdrawal preparation and have been able to use it to provide direct evidence that plasticity of monosynaptic PSPs from LE sensory neurons contributes to habituation, dishabituation, and sensitization of the reflex response. We have found that monosynaptic PSPs from LE sensory neurons to LFS motor neurons make a substantial contribution to the behavioral response in the siphonwithdrawal preparation and that there is a good fit between both the amplitude and duration of plasticity of the monosynaptic PSPs and plasticity of the behavior during habituation, dishabituation, and sensitization.

Although encouraging, the fit between plasticity of the PSPs and behavior is in fact somewhat surprising. We have estimated that monosynaptic PSPs from LE sensory neurons contribute $60 \%$ of the complex PSP in LFS motor neurons and that LFS neurons (and all central neurons) in turn contribute $55 \%$ of the behavioral response, so that the monosynaptic PSPs should contribute approximately one-third of the behavioral response. These results imply that the other central and peripheral components of the reflex undergo plasticity similar to that of the monosynaptic PSPs from LE to LFS neurons. We have found that tail shock produces peripheral enhancement that is roughly similar to plasticity of the monosynaptic PSPs during dishabituation and sensitization (Fig. 8). Frost et al. (1997) earlier found that plasticity of monosynaptic PSPs from other as yet unidentified sensory neurons also appears to be similar to plasticity of PSPs from the LE sensory neurons during habituation, dishabituation, and sensitization in the gill-withdrawal preparation. Furthermore, plasticity of PSPs from LE neurons to peripheral motor neurons is similar to plasticity of PSPs to central motor neurons during a neural analog of habituation (Bailey et al., 1979). Plasticity of the polysynaptic component of the reflex might also be similar if it were primarily attributable to plasticity of the monosynaptic input from sensory neurons to interneurons. However, although plasticity of the monosynaptic PSPs, complex PSPs, motor neuron firing, and behavior were similar during habituation, dishabituation, and sensitization overall (Fig. 15), there were some more subtle differences between motor neuron firing and the complex 
A
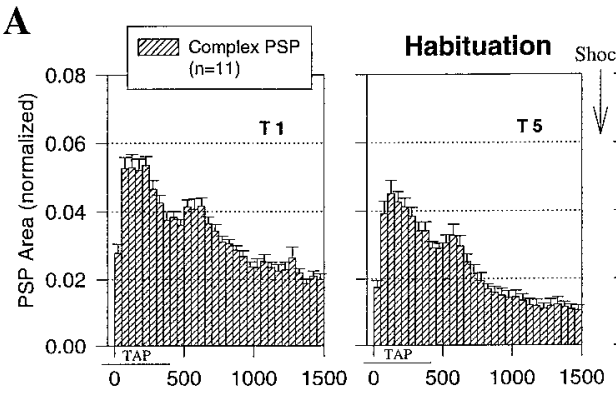

Shock

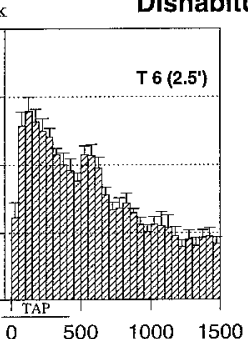

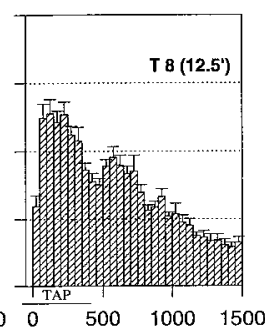

ishabituation

B

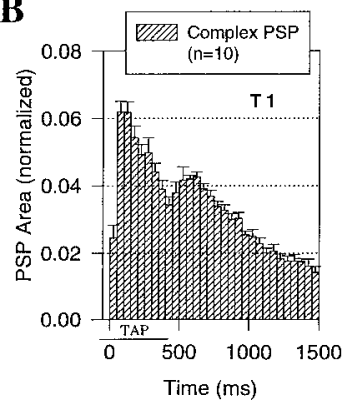

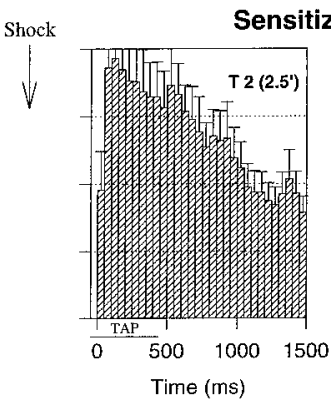

Time (ms)

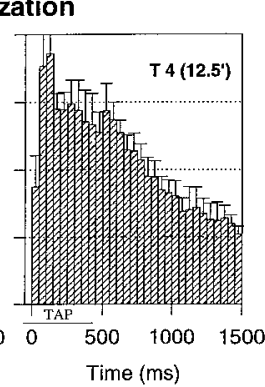

Figure 11. The average shape of the complex PSP in an $\mathrm{LFS}_{\mathrm{B}}$ neuron during habituation and dishabituation $(A)$ and sensitization $(B)$ in the same experiments as Figure 10. The PSP in each $50 \mathrm{msec}$ interval has been normalized to the total area on trial 1 in each experiment (average on trial $1=49,627 \pm 5371 \mathrm{mV} \times$ $\mathrm{msec}$ in $A$ and $49,844 \pm 5206 \mathrm{mV} \times \mathrm{msec}$ in $B)$.
PSP, and between dishabituation and sensitization, when we examined changes in the shapes of the responses (Figs. 7, 11). These more subtle differences are probably attributable to differences in plasticity of excitatory and inhibitory interneurons in the polysynaptic component of the reflex, which would thus also contribute to plasticity of the behavior.

\section{Comparison with the gill-withdrawal preparation}

Having two simplified preparations has allowed us to compare plasticity of the gill- and siphon-withdrawal components of the reflex. Such comparisons have revealed a number of similarities but also some important differences between the two preparations. In both preparations, habituation appears to be attributable primarily to homosynaptic depression of monosynaptic PSPs from siphon sensory neurons. Also, in both preparations, dishabituation and sensitization involve facilitation of the monosynaptic component of the PSP that is maximal 2.5 min after the shock, as well as peripheral enhancement that is also maximal $2.5 \mathrm{~min}$ after the shock and is associated with an increase in spontaneous firing of the motor neurons.

Although in the siphon-withdrawal preparation the facilitation of monosynaptic PSPs has approximately the same amplitude and duration as facilitation of complex PSPs, increased firing of motor neurons, and increased siphon withdrawal, in the gill-withdrawal preparation there are dissociations between facilitation of the monosynaptic component of the PSP and the other response measures (Cohen et al., 1997). First, although maximal facilitation of the monosynaptic PSP occurs 2.5 min after the shock, in the gill-withdrawal preparation the maximal increases in withdrawal, evoked firing of the motor neuron, and the complex PSP all occur $12.5 \mathrm{~min}$ after the shock and are therefore thought to involve an important contribution from plasticity in interneurons. The time of maximal dishabituation or sensitization has similarly ranged from 2 or $3 \mathrm{~min}$ to $>20 \mathrm{~min}$ in studies on intact animals (Pinsker et al., 1970; Mackey et al., 1987; Marcus et al., 1988; Hawkins et al., 1998a).

Second, in the gill-withdrawal preparation when facilitation of the monosynaptic PSP is maximal, there are relatively small increases or no change in the behavior and firing of the motor
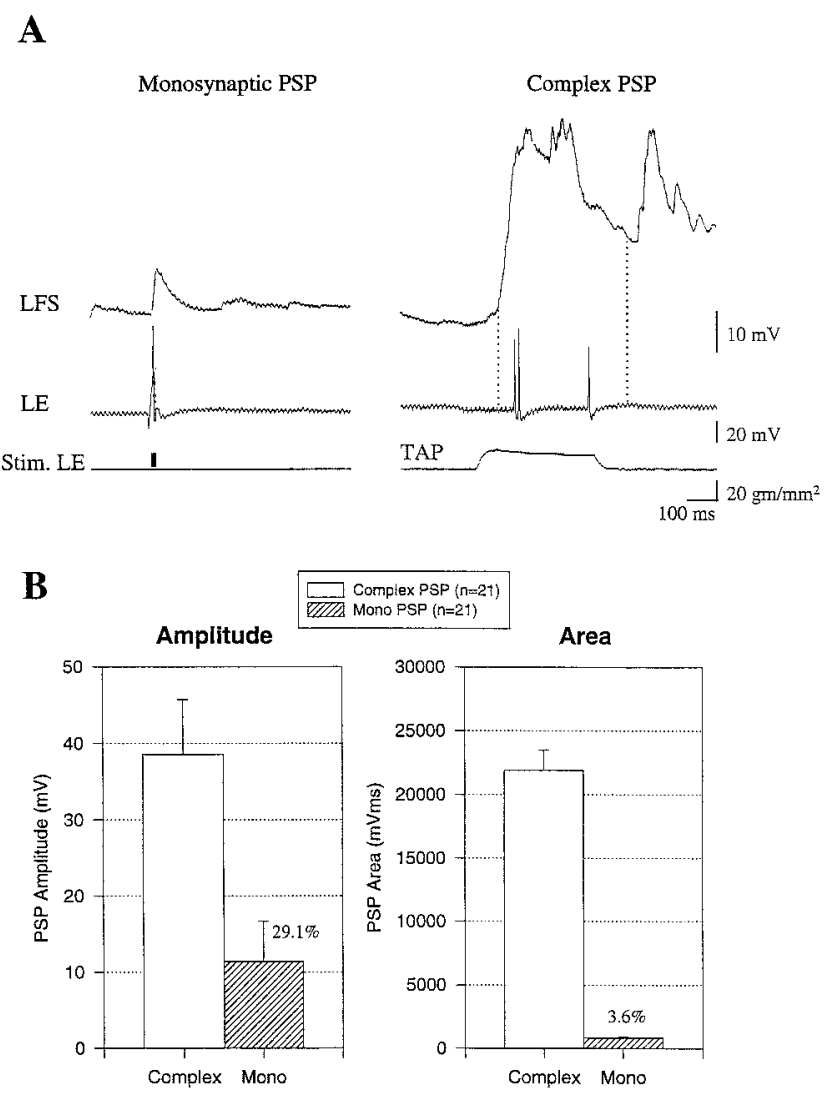

Figure 12. Direct contribution of monosynaptic PSPs from LE neurons to the complex PSP in $\mathrm{LFS}_{\mathrm{B}}$ neurons. $A$, Examples of the monosynaptic PSP produced in an $\mathrm{LFS}_{\mathrm{B}}$ neuron by intracellular stimulation of an LE neuron and the complex PSP produced by a siphon tap, measured $\sim 10 \mathrm{sec}$ apart under identical conditions. $B$, The average amplitude (left) and area (right) of the monosynaptic and complex PSPs in experiments like the one shown in $A$. The area of the complex PSP was measured in the interval indicated by the dotted lines in $A$, which is when LE neurons fire and contribute directly to the complex PSP (see Fig. 7). 
A
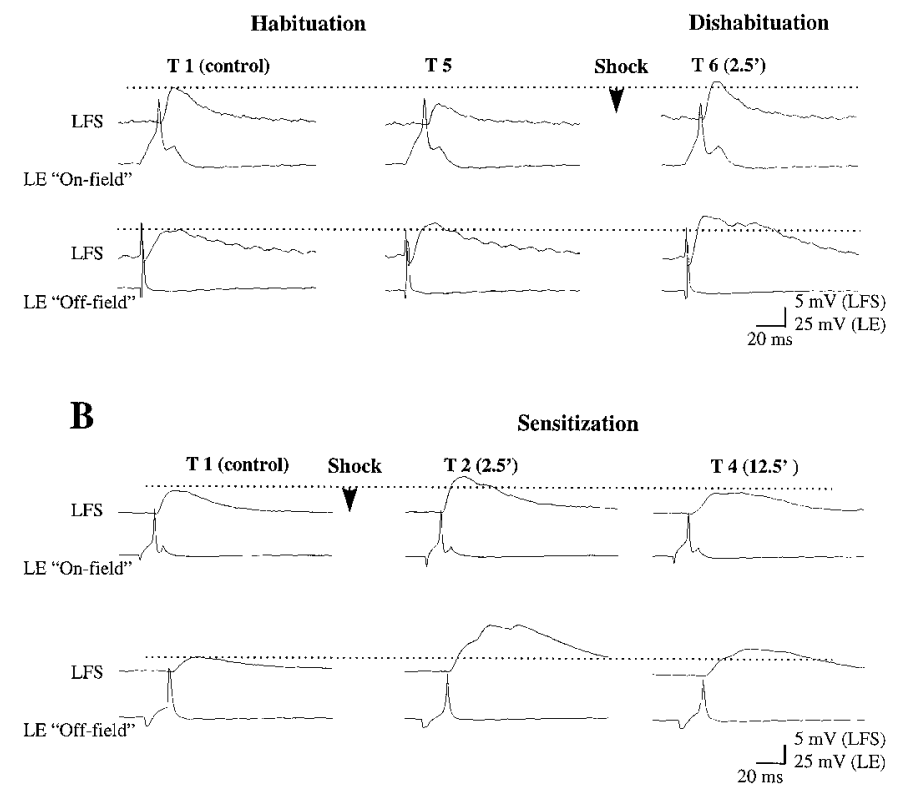

Figure 13. Records from representative experiments showing the monosynaptic PSP produced in an $\mathrm{LFS}_{\mathrm{B}}$ neuron by intracellular stimulation of an on-field or off-field LE neuron $\sim 10 \mathrm{sec}$ before the siphon tap on trials 1 and 5 during habituation and trials $6-8$ during dishabituation $(A)$, and before each trial during sensitization $(B)$.

neuron and an actual decrease in the complex PSP (Cohen et al., 1997). Wright et al. (1991) observed similar dissociations between monosynaptic and complex PSPs and suggested that they could be attributable to the contribution to the complex PSP of unidentified sensory neurons with different plasticity than the LE sensory neurons. However, the monosynaptic component of the PSP in the gill-withdrawal preparation was measured by stimulating the siphon with the abdominal ganglion bathed in high divalent seawater (which reduces the polysynaptic component) and therefore included the contribution of any unidentified sensory neurons (Cohen et al., 1997). Thus, the dissociation between the monosynaptic and complex PSP was more likely caused by transient inhibition of interneurons involved in the polysynaptic component. Such transient inhibition has also been observed behaviorally for some components of the gill- and siphon-withdrawal reflex (Mackey et al., 1987; Marcus et al., 1988) but not for others (Hawkins et al., 1998a), and in particular does not occur for the "flaring" response that is thought to be measured in the siphonwithdrawal preparation (Illich et al., 1994). Thus, the simpler pattern of behavioral and cellular results in the siphon-withdrawal preparation may be attributable in part to the lack of transient inhibition of interneurons involved in the particular response measured in that preparation.

Similarly, although in the siphon-withdrawal preparation increases in monosynaptic PSPs, complex PSPs, firing of the motor neurons, and behavior were all approximately the same during dishabituation as during sensitization (Fig. 15), in the gillwithdrawal preparation there were dissociations between dishabituation and sensitization (Cohen et al., 1997). In particular, facilitation of the complex PSP in the gill motor neuron was larger (or transient inhibition was smaller) during dishabituation than during sensitization. Similar dissociations have been observed at both the behavioral and cellular levels for some components of the gill- and siphon-withdrawal reflex (Mackey et al., 1987; Mar-
A

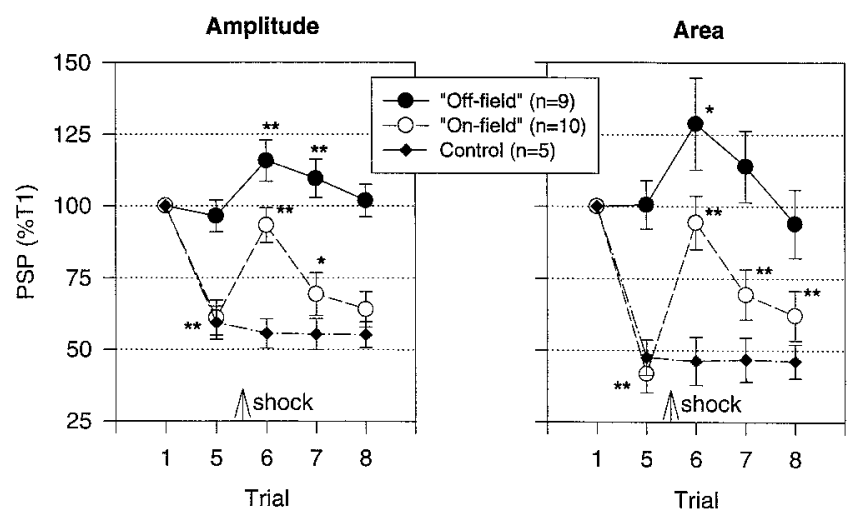

B

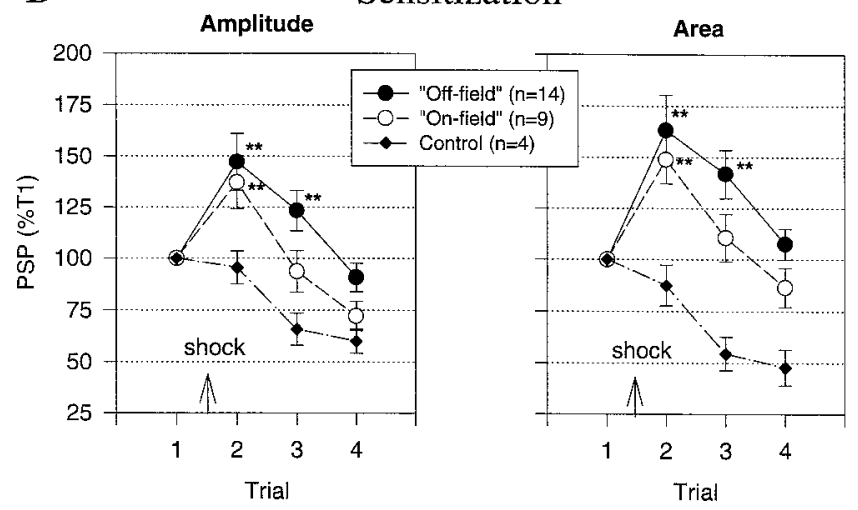

Figure 14. Average amplitude (left) and area (right) of the monosynaptic PSP produced in an $\mathrm{LFS}_{\mathrm{B}}$ neuron by intracellular stimulation of an on-field or off-field LE neuron during habituation and dishabituation $(A)$ and sensitization $(B)$. The average values on trial 1 were $12.0 \pm 1.5 \mathrm{mV}$ and $659 \pm 104 \mathrm{mV} \times \mathrm{msec}$ (Dishabituation, on-field), $12.0 \pm 1.9 \mathrm{mV}$ and $824 \pm 155 \mathrm{mV} \times \mathrm{msec}$ (Dishabituation, off-field), $9.8 \pm 2.0 \mathrm{mV}$ and $629 \pm$ $144 \mathrm{mV} \times \operatorname{msec}$ (Dishabituation, no shock control), $9.0 \pm 1.1 \mathrm{mV}$ and $703 \pm 114 \mathrm{mV} \times \operatorname{msec}$ (Sensitization, on-field), $10.9 \pm 1.4 \mathrm{mV}$ and $880 \pm$ $115 \mathrm{mV} \times \operatorname{msec}$ (Sensitization, off-field), $13.9 \pm 3.5 \mathrm{mV}$ and $874 \pm 247$ $\mathrm{mV} \times \mathrm{msec}$ (Sensitization, control); not significantly different.

cus et al., 1988; Wright et al., 1991), and these dissociations as well as other lines of evidence (Hochner et al., 1986; Rankin and Carew, 1988) have suggested that dishabituation and sensitization might involve different underlying mechanisms. However, such dissociations have not been observed for other components of the reflex in intact animals (Hawkins et al., 1998a) or in the siphon-withdrawal preparation, indicating that they are not universal. Moreover, the dissociations between dishabituation and sensitization have only been observed under circumstances when transient inhibition was also observed, suggesting that they may be attributable, at least in part, to an interaction between habituation and inhibition rather than a fundamental difference between dishabituation and sensitization. In the siphon-withdrawal preparation, there appears to be no transient inhibition and also no difference between the major cellular mechanisms contributing to dishabituation and sensitization insofar as we have examined them, although such a difference cannot be excluded. There were some more subtle differences between dishabituation and sensitization, and also between motor neuron firing and the complex PSP, when we examined changes in the shapes of the responses (Figs. 7, 11). However, these were the reverse of similar changes observed in the gill-withdrawal preparation (Cohen et 
SWR amplitude $(\mathrm{mm})$ LFS and LE frequency $(\mathrm{Hz})$

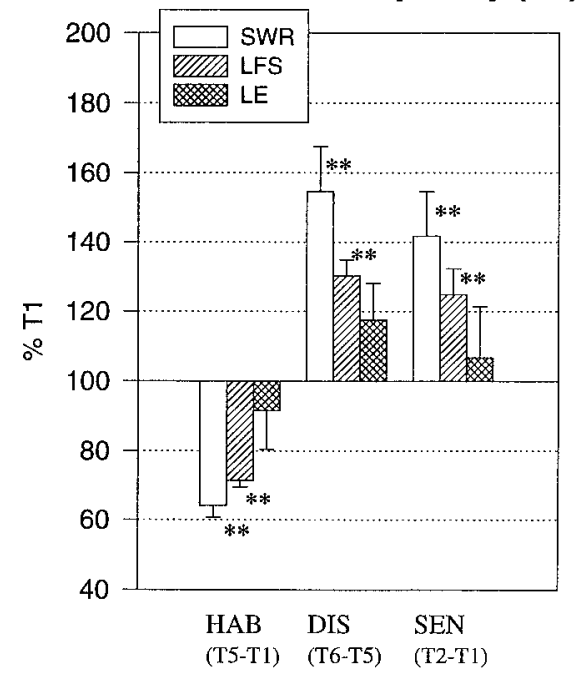

PSP Area (mVms)

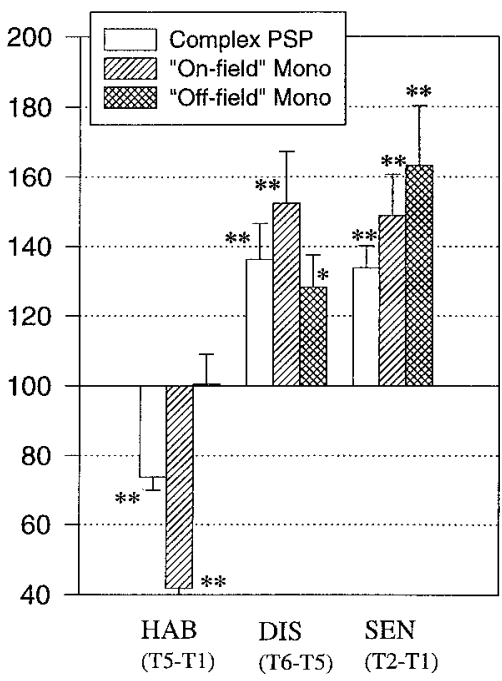

Figure 15. Summary of habituation, dishabituation, and sensitization of the siphon withdrawal reflex at different levels of analysis. For comparative purposes, all responses are expressed as percentage of trial $1(T 1)$. al., 1997), suggesting that learning in the two preparations involves different plasticity in interneurons participating in the two components of the reflex.

These differences between the gill- and siphon-withdrawal preparations illustrate that the withdrawal is not unitary but has distinguishable components that make different contributions to the observed behavior depending on the experimental circumstances and undergo different plasticity during learning. Similar results have been observed in intact animals (Hawkins et al., 1998a). These findings demonstrate the importance of examining cellular mechanisms of learning under the same circumstances and preferably at the same time as the behavior. The simplified gill- and siphon-withdrawal preparations have made it possible for us to do that. Our studies of these preparations have provided the first direct evidence that plasticity of monosynaptic PSPs contributes to learning and memory for habituation, dishabituation, and sensitization of the reflex, and they have shed new light on the relationship between dishabituation and sensitization. It will now be interesting to examine how plasticity of the gill- and siphonwithdrawal components of the reflex are integrated during these forms of learning and to perform a similar analysis of classic conditioning in these preparations (Hawkins et al., 1998b; our unpublished observations).

\section{REFERENCES}

Antonov IN, Osipenko ON, Storozhyk VM (1991) Analysis of heterosynaptic facilitation in identified giant neurons from cerebral ganglion of the pond snail Planorbis corneus. Comp Biochem Physiol 98C:323-327.

Bailey CH, Castellucci VF, Koester J, Kandel ER (1979) Cellular studies of peripheral neurons in siphon skin of Aplysia californica. J Neurophysiol 42:530-557.

Bliss TVP, Collingridge G (1993) A synaptic model of memory: longterm potentiation in the hippocampus. Nature 361:31-39.

Byrne JH, Castellucci VF, Kandel ER (1974) Receptive fields and response properties of mechanoreceptor neurons innervating siphon skin and mantle shelf of Aplysia. J Neurophysiol 37:1041-1064.

Byrne JH, Castellucci VF, Kandel ER (1978) Contribution of individual mechanoreceptor sensory neurons to defensive gill-withdrawal reflex in Aplysia. J Neurophysiol 41:418-431.

Carew TJ, Castellucci VF, Kandel ER (1971) An analysis of dishabituation and sensitization of the gill-withdrawal reflex in Aplysia. Int J Neurosci 2:79-98.
Carew TJ, Walters ET, Kandel ER (1981) Classical conditioning in a simple withdrawal reflex in Aplysia californica. J Neurosci 1:1426-1437.

Castellucci VF, Pinsker H, Kupfermann I, Kandel ER (1970) Neuronal mechanisms of habituation and dishabituation of the gill-withdrawal reflex in Aplysia. Science 167:1745-1748.

Cohen TE, Kaplan SW, Kandel ER, Hawkins RD (1997) A simplified preparation for relating cellular events to behavior: mechanisms contributing to habituation, dishabituation, and sensitization of the Aplysia gill-withdrawal reflex. J Neurosci 17:2887-2900.

Colebrook E, Lukowiak K (1988) Learning by the Aplysia model system: lack of correlation between gill and gill motor neuron responses. J Exp Biol 135:411-429.

Frost L, Kaplan SW, Cohen TE, Henzi V, Kandel ER, Hawkins RD (1997) A simplified preparation for relating cellular events to behavior: contribution of LE and unidentified siphon sensory neurons to mediation and habituation of the Aplysia gill- and siphon-withdrawal reflex. J Neurosci 17:2901-2914.

Frost WN, Kandel ER (1995) Structure of the network mediating siphon-elicited siphon withdrawal in Aplysia. J Neurophysiol 73:2413-2427.

Frost WN, Clark GA, Kandel ER (1988) Parallel processing of shortterm memory for sensitization in Aplysia. J Neurobiol 19:297-334.

Goldberg JI, Lukowiak K (1984) Transfer of habituation in Aplysia: contribution of heterosynaptic pathways in habituation of the gillwithdrawal reflex. J Neurobiol 15:395-411.

Hawkins RD, Castellucci VF, Kandel ER (1981) Interneurons involved in mediation and modulation of gill-withdrawal reflex in Aplysia. II. Identified neurons produce heterosynaptic facilitation contributing to behavioral sensitization. J Neurophysiol 45:315-326.

Hawkins RD, Abrams TW, Carew TJ, Kandel ER (1983) A cellular mechanism of classical conditioning in Aplysia: activity-dependent amplification of presynaptic facilitation. Science 219:400-405.

Hawkins RD, Clark GA, Kandel ER (1987) Cell biological studies of learning in simple vertebrate and invertebrate systems. In: Handbook of physiology, Section 1: the nervous system, Vol V, Higher functions of the brain, Part 1 (Mountcastle VB, Plum F, Geiger SR, eds), pp 25-83. Bethesda, MD: American Physiological Society.

Hawkins RD, Kandel ER, Siegelbaum SA (1993) Learning to modulate transmitter release: themes and variations in synaptic plasticity. Annu Rev Neurosci 16:625-655.

Hawkins RD, Cohen TE, Greene W, Kandel ER (1998a) Relationships between dishabituation, sensitization, and inhibition of the gill- and siphon-withdrawal reflex in Aplysia californica: effects of response measure, test time, and training stimulus. Behav Neurosci 112:24-38.

Hawkins RD, Greene W, Kandel ER (1998b) Classical conditioning, differential conditioning, and second-order conditioning of the Aplysia gill-withdrawal reflex in a simplified mantle organ preparation. Behav Neurosci 112:636-645. 
Hickie C, Walters ET (1995) Motor neuronal control of tail-directed and head-directed siphon responses in Aplysia californica. J Neurophysiol 74:307-321.

Hickie C, Cohen LB, Balaban PM (1997) The synapse between LE sensory neurons and gill motoneurons makes only a small contribution to the Aplysia gill-withdrawal reflex. Eur J Neurosci 9:627-636.

Hochner B, Klein M, Schacher S, Kandel ER (1986) Additional component in the cellular mechanism of presynaptic facilitation contributes to behavioral dishabituation in Aplysia. Proc Natl Acad Sci USA 83:8794-8798.

Illich PA, Joynes RL, Walters ET (1994) Response-specific inhibition during general facilitation of defensive responses in Aplysia. Behav Neurosci 108:614-623.

Ito M (1989) Long-term depression. Annu Rev Neurosci 12:85-102.

Jacklet JW, Rine J (1977) Facilitation at neuromuscular junctions: contribution to habituation and dishabituation of the Aplysia gill withdrawal reflex. Proc Natl Acad Sci USA 74:1267-1271.

Kanz JE, Eberly LB, Cobbs JS, Pinsker HM (1979) Neuronal correlates of siphon withdrawal in freely behaving Aplysia. J Neurophysiol 42:1538-1556.

Kupfermann I, Castellucci VF, Pinsker H, Kandel ER (1970) Neuronal correlates of habituation and dishabituation of the gill-withdrawal reflex in Aplysia. Science 167:1743-1745.

Linden DJ, Connor JA (1995) Long-term synaptic depression. Annu Rev Neurosci 18:319-357.

Lukowiak K (1986) In vitro classical conditioning of a gill withdrawal reflex in Aplysia. Neural correlates and possible neural mechanisms. J Neurobiol 17:83-101.

Mackey SL, Glanzman DL, Small SA, Dyke AM, Kandel ER, Hawkins RD (1987) Tail shock produces inhibition of the siphon-withdrawal reflex in Aplysia: possible behavioral role for presynaptic inhibition mediated by the peptide Phe-Met-Arg-Phe-NH2. Proc Natl Acad Sci USA 84:8730-8734.
Mackey SL, Kandel, ER, Hawkins RD (1989) Identified serotonergic neurons LCB1 and RCB1 in the cerebral ganglia of Aplysia produce presynaptic facilitation of siphon sensory neurons. J Neurosci 9:4227-4235.

Marcus EA, Nolen TG, Rankin CH, Carew TJ (1988) Behavioral dissociation of dishabituation, sensitization, and inhibition in Aplysia. Science 241:210-213.

Perlman AJ (1979) Central and peripheral control of siphon-withdrawal reflex in Aplysia californica. J Neurophysiol 42:510-529.

Pinsker H, Kupfermann I, Castellucci V, Kandel ER (1970) Habituation and dishabituation of the gill-withdrawal reflex in Aplysia. Science 167:1740-1742.

Rankin CH, Carew TJ (1988) Dishabituation and sensitization emerge as separate processes during development in Aplysia. J Neurosci 8:197-211.

Stopfer M, Carew TJ (1996) Heterosynaptic facilitation of tail sensory neuron synaptic transmission during habituation in tail-induced tail and siphon withdrawal reflexes of Aplysia. J Neurosci 16:4933-4948.

Trudeau LE, Castellucci VF (1992) Contribution of polysynaptic pathways in the mediation and plasticity of the Aplysia gill and siphon withdrawal reflex: evidence for differential modulation. J Neurosci 12:3838-3848.

Trudeau LE, Castellucci VF (1993) Sensitization of the gill and siphon withdrawal reflex of Aplysia: multiple sites of change in the neuronal network. J Neurophysiol 70:1210-1220.

Walters ET, Cohen LB (1997) Functions of the LE sensory neurons in Aplysia. Invert Neurosci 3:15-25.

Walters ET, Byrne JH, Carew TJ, Kandel ER (1983) Mechanoafferent neurons innervating tail of Aplysia. II. Modulation by sensitizing stimuli. J Neurophysiol 50:1543-1559.

Wright WG, Marcus EA, Carew TJ (1991) A cellular analysis of inhibition in the siphon withdrawal reflex of Aplysia. J Neurosci 11:24982509. 